\title{
Hyaline membrane disease, alkali, and intraventricular haemorrhage
}

\author{
J. S. WIGGLESWORTH, I. H. KEITH, D. J. GIRLING,^ and S. A. SLADE \\ From the Department of Paediatrics and Neonatal Medicine, Institute of Child Health, Hammersmith Hospital, \\ London
}

Wigglesworth, J. S., Keith, I. H., Girling, D. J., and Slade, S. A. (1976). Archives of Disease in Childhood, 51, 755. Hyaline membrane disease, alkali, and intraventricular haemorrhage. The relation between intraventricular haemorrhage (IVH) and hyaline membrane disease (HMD) was studied in singletons that came to necropsy at Hammersmith Hospital over the years 1966-73. The incidence of IVH in singleton live births was $3 \cdot 22 / 1000$ and of HMD 4.44/1000. Although the high figures were partly due to the large number of low birthweight infants born at this hospital, the incidence of IVH in babies weighing 1001-1500 g was three times as great as that reported in the 1958 British Perinatal Mortality Survey. Most IVH deaths were in babies with HMD, but the higher frequency of IVH was not associated with any prolongation of survival time of babies who died with HMD as compared with the 1958 survey. IVH was seen frequently at gestations of up to 36 weeks in babies with HMD but was rare above 30 weeks' gestation in babies without HMD. This indicated that factors associated with HMD must cause most cases of IVH seen at gestations above 30 weeks.

Comparison of clinical details in infants with HMD who died with or without IVH (at gestations of 30-37 weeks) showed no significant differences between the groups other than a high incidence of fits and greater use of alkali therapy in the babies with IVH. During the 12 hours when most alkali therapy was given, babies dying with IVH received a mean total alkali dosage of $10.21 \mathrm{mmol} / \mathrm{kg}$ and those dying without IVH $6.34 \mathrm{mmol} / \mathrm{kg}(\mathrm{P}<0 \cdot 001)$. There was no difference in severity of hypoxia or of metabolic acidosis between the 2 groups. Babies who died with HMD and germinal layer haemorrhage (GLH) without IVH had received significantly more alkali than those who died with HMD alone, whereas survivors of severe respiratory distress syndrome had received lower alkali doses than other groups.

It is suggested that the greatly increased death rate from IVH in babies with HMD indicates some alteration of management of HMD (since 1958) as a causative factor. Liberal use of hypertonic alkali solutions is the common factor which distinguishes babies dying with GLH and IVH from other groups of babies with HMD. Although the causal nature of this association remains unproved, it seems justifiable to urge caution in alkali usage.

The growing importance of intraventricular haemorrhage (IVH) as a cause of death in low birthweight preterm infants has been reflected in recent years by an increasing number of clinical and pathological studies on this condition. The

Received 28 January 1976

^Present address: MRC Tuberculosis and Chest Diseases Unit, Brompton Hospital, London SW3 $6 \mathrm{HP}$. aetiology and pathology of IVH have been investigated by Larroche (1964), Towbin (1968), Leech and Kohnen (1974), Cole et al. (1974), and Hambleton and Wigglesworth (1976). The timing of the lesion has received attention by Tsiantos et al. (1974), and clinicopathological relationships by Amiel (1964), Fedrick and Butler (1970b), and Harcke et al. (1972). It has been suggested that 
IVH may result from disseminated intravascular coagulation (Gray, Ackerman, and Frazer, 1968), though this has been denied (Chessells and Wigglesworth, 1971). Several studies have investigated the possibility that nontraumatic intracranial haemorrhage (including IVH) may be related to high sodium bicarbonate dosage administered during treatment for respiratory distress (Simmons et al., 1972; Roberton and Howat, 1975; Anderson et al., 1976).

In those clinicopathological studies where sufficient cases have been available for detailed analysis a problem has been a lack of adequate information on one or other important aspect, such as the background population, clinical details of the babies, or the post-mortem pathology. In addition, the possibility that treatment of the respiratory distress syndrome might predispose to death from IVH clearly demands further study of the relation between the two conditions. We have therefore begun a clinicopathological study of IVH using our perinatal data bank and computer facilities. This communication details the material involved, the methods of study, and our findings on the relation between IVH and hyaline membrane disease (HMD) in singletons.

\section{Materials and methods}

Over the years 1966-73 there were 2244 admissions to the neonatal unit at Hammersmith Hospital. Necropsies which were performed on 535 of the 571 neonatal deaths showed IVH in 176 cases and HMD in 285 (Table I). Twins and babies with severe Rhesus isoimmunization or malformations have been excluded from further consideration to allow study of the birth-

\section{TABLE I}

Admissions to Hammersmith Neonatal Unit 1966-73, and cases with different categories of IVH and HMD at necropsy

\begin{tabular}{l|c|c|c}
\hline & Total & $\begin{array}{c}\text { Hammersmith } \\
\text { births }\end{array}$ & $\begin{array}{c}\text { Other } \\
\text { hospitals }\end{array}$ \\
\hline $\begin{array}{l}\text { Admissions to } \\
\text { neonatal unit }\end{array}$ & 2244 & 1472 & 772 \\
$\begin{array}{l}\text { Necropsies } \\
\text { IVH }\end{array}$ & 535 & 225 & 310 \\
HMD & 176 & 59 & 117 \\
Singleton-IVH† & 285 & 94 & 191 \\
Singleton- & 130 & 50 & 80 \\
'typical' IVH†† & 111 & 42 & 69 \\
Singleton- & 201 & 69 & 132 \\
HMDt & & & \\
\hline
\end{tabular}

^Post-mortem rate $94 \%$.

tExcluding serious malformations and $R h$ isoimmunization ‡'Typical' IVH defined in text. weight and gestational age correlations of IVH and to facilitate comparison with the 1958 British Perinatal Mortality Survey findings (Fedrick and Butler, 1970a, b). For the 4 years 1970-73, information from all infants born at the hospital, or admitted to the neonatal unit from other hospitals, was available from our perinatal data bank. To the data bank have been added further information on all neonatal deaths from the years 196669. By supplementing the data on livebirths for the years 1970-73 with data from earlier years recorded routinely on neonatal unit admissions, and with information from the obstetric department's annual records, a singleton livebirth population at this hospital of 15545 has been established for the years 1966-73.

Most post-mortem examinations were carried out by one of us (J.S.W.), and after fixation the brain was usually examined by a neuropathologist. It was thus possible to subdivide IVH according to the origin of the haemorrhage.

The brain pathology reports showed that in 111 cases IVH was associated with anterior germinal layer haemorrhage (GLH) (haemorrhage over the head or body of the caudate nucleus) or was described as 'massive IVH' without mention of a site of origin. Since the babies with massive IVH had similar characteristics to those in whom GLH was recorded they have been included in the same group as 'typical IVH' (Table I). The remaining 19 brains showed diffuse IVH without GLH (probably of choroid plexus origin), or IVH associated with GLH in the occipital or temporal horns and these have been separated into an 'atypical IVH' group and are considered only in the estimates of total incidence. Clinicopathological correlations have involved several subgroups of the 111 babies with typical IVH and the 115 singleton babies with HMD without IVH.

Computer analyses were performed using a suite of programs which print out the frequency of occurrence of required correlations in the form of birthweight/ gestation tables. Correlations which appeared significant were examined further by printing out the relevant case numbers and reanalysing the data with additional information from the original case notes. The data bank has thus been used to test out hypotheses and select subsets of the cases for further analysis before extracting case notes from the files. All data reported in this paper have been confirmed by reference to the appropriate source documents.

Statistical analyses were performed using Student's ' $t$ ', Wilcoxon's Rank Sum, and $\chi^{2}$ test as appropriate. Dosages of individual alkali solutions have been expressed in terms of $\mathrm{mmol} / \mathrm{kg}$ birthweight and doses of THAM (Tris-hydroxymethyl-aminomethane) and sodium bicarbonate have been added in this way, since there is evidence that the osmotic effects of THAM in vivo are as great as those of equimolar solutions of bicarbonate (Heird et al., 1972). As an alternative we have calculated the osmolar load using the figures of $1680 \mathrm{mOsm} / \mathrm{kg}$ water for $8.4 \%$ sodium bicarbonate and $708 \mathrm{mOsm} / \mathrm{kg}$ water for $7 \%$ THAM given by Baum and Roberton (1975). 
Alkali administration was not carried out according to a consistent technique as the infants were admitted at varying ages from more than a dozen different hospitals where procedures differed widely. The most frequent mode of administration was by repeated injections of 1-10 ml of solutions of molar (8.4\%) sodium bicarbonate or $0.58 \mathrm{~mol} / 1(7 \%)$ THAM through an umbilical venous catheter. Blood gas estimations were performed on samples obtained from the lower aorta through an umbilical arterial catheter, though radial artery samples were used occasionally. Plasma electrolyte levels and haematocrits were measured too infrequently to allow analysis in relation to alkali dosage or timing of IVH. Other aspects of care of the infants while in the neonatal unit were according to principles previously published (Davies et al., 1972).

\section{Results}

Incidence and birthweight/gestation distribution of infants with IVH and HMD. There was a very high incidence of IVH $(3 \cdot 22 / 1000$ livebirths) and HMD (4.44/1000 livebirths) in the singleton birth population in this hospital. This was partly explained by the large number of babies of $2000 \mathrm{~g}$ birthweight or less born at the hospital $(2 \cdot 46 \%$ of livebirths as compared to an estimated $1 \cdot 18 \%$ reported by Fedrick and Butler, 1970a). After making allowance for this difference in population the incidences still remained higher than those of the 1958 series. We therefore looked at the incidence of the conditions by birthweight groups and compared them, where possible, with the figures quoted by Federick and Butler (1970a, b) (Table II). The most striking feature was the high incidence of IVH in babies of 1001-1500 g birthweight, which is three times that reported by Fedrick and Butler (1970b), a highly significant difference $(P<0.0001)$. Most of these deaths were accounted for by the IVH with HMD group (173/1000 livebirths). This figure is greater than that quoted by Fedrick and Butler (1970a) for all cases of HMD in babies of the same birthweight group, and largely explains the high overall incidence of fatal HMD in babies born in this hospital. Other features to be seen in Table II are the predominance of IVH without HMD in the babies of $1000 \mathrm{~g}$ birthweight and less, and the low incidence of fatal HMD in infants of birthweight above $1500 \mathrm{~g}$ though the latter is not significant.

Since it has been suggested that the increasing incidence of IVH in infants dying with HMD may be due to the survival of a larger number of such babies until the age when IVH supervenes (Machin, 1975), we compared the survival times of our infants with those reported from the British Perinatal Mortality Survey (Fig. 1). It can be seen that the length of survival of the infants in the two series is virtually identical, with death occurring most

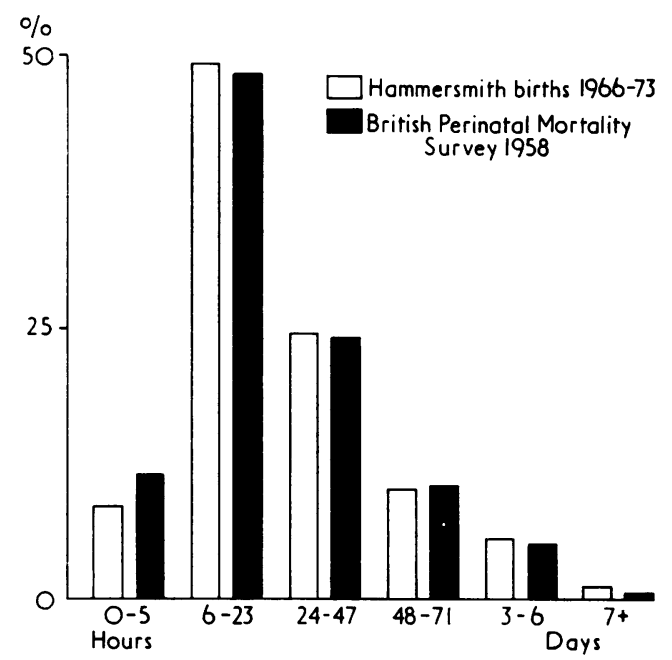

FIG. 1.-Age at death in babies with HMD.

TABLE II

Deaths with proven HMD and IVH in singletons by birthweight

\begin{tabular}{|c|c|c|c|c|c|c|c|}
\hline \multirow{2}{*}{ Birthweight (g) } & \multicolumn{5}{|c|}{ Hammersmith Hospital births, 1966-73 } & \multicolumn{2}{|c|}{ Fedrick \& Butler (1970a, b) } \\
\hline & IVH & HMD & $\underset{\text { IVH }}{\text { HMD }}+$ & $\begin{array}{l}\text { Total } \\
\text { IVH }\end{array}$ & $\begin{array}{l}\text { Total } \\
\text { HMD }\end{array}$ & $\begin{array}{l}\text { Total } \\
\text { IVH }\end{array}$ & $\begin{array}{l}\text { Total } \\
\text { HMD }\end{array}$ \\
\hline $\begin{array}{c}<1000 \\
1001-1500 \\
1501-2000 \\
2001-2500 \\
2501-3000 \\
3001+ \\
\text { All birthweights }\end{array}$ & $\begin{array}{c}185 \\
81 \cdot 8 \\
1 \cdot 00 \\
0 \cdot 1 \\
1 \cdot 35\end{array}$ & $\begin{array}{c}167 \\
118 \\
27 \cdot 4 \\
3 \cdot 01 \\
2 \cdot 04 \\
2 \cdot 57\end{array}$ & $\begin{array}{c}55 \cdot 6 \\
173 \\
18 \cdot 3 \\
1 \cdot 00 \\
0 \cdot 51 \\
- \\
1 \cdot 87\end{array}$ & $\begin{array}{l}241 \\
255^{\star} \\
18 \cdot 3 \\
2 \cdot 00 \\
0 \cdot 51 \\
0 \cdot 1 \\
3 \cdot 22\end{array}$ & $\begin{array}{c}222 \\
291 \dagger \\
45 \cdot 7 \\
4 \cdot 01 \\
2 \cdot 55 \\
-\overline{4 \cdot 44}\end{array}$ & $\begin{array}{l}275 \\
79 \cdot 7 \star \\
23 \cdot 4 \\
2 \cdot 0 \\
0 \cdot 3 \\
0 \cdot 1 \\
1 \cdot 1\end{array}$ & $\begin{array}{l}236 \\
166 t \\
85 \cdot 4 \\
11 \cdot 4 \\
1 \cdot 3 \\
0 \cdot 1 \\
2 \cdot 5\end{array}$ \\
\hline
\end{tabular}

Note: Figures indicate deaths per 1000 livebirths, excluding Rhesus isoimmunization and malformations.

$\star \mathrm{P}<0.0001 ; \quad+\mathrm{P}<0.01$. 
frequently between 6 and 24 hours age. Comparison of the age at death of the low gestational age groups only did not alter the finding.

Analysis of the frequency distribution of IVH deaths by gestation and birthweight, both those delivered at Hammersmith and the outside admissions, showed significant differences according to whether they also had coexisting HMD (Fig. 2).

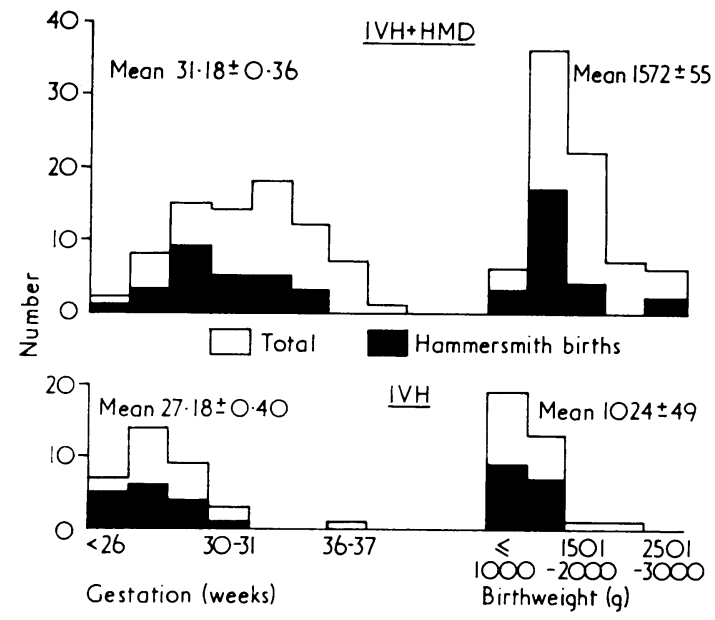

FIG. 2.-Frequency distribution by gestation and birthweight of babies with intraventricular haemorrhage $(I V H)$ with and without hyaline membrane disease (HMD). Birthweight and gestation distributions are highly significantly different $\left(P<10^{-6}\right.$ for each comparison).

IVH was seen commonly in infants with HMD at up to 36 weeks, but was rare above 30 weeks in infants without HMD. Birthweight differences followed a similar pattern. The similarity of the distributions in the population of babies born at Hammersmith shows that the difference was not due to any bias in admission of cases from other hospitals.

From this striking difference in gestation and birthweight distribution we deduced that some factor or factors associated with HMD must be responsible for nearly all cases of IVH ocurring at gestations of 30 weeks or more. We therefore compared the clinical features of infants of 30-37 weeks' gestation who died with HMD and IVH with those of infants of the same gestational age who died with HMD without IVH.

Comparison of infants of $30-37$ weeks' gestation dying with HMD with or without IVH. Most clinical features relating to the mothers and babies showed no difference between the two groups (Table III). There was a tendency for the babies who died with IVH to be smaller and less mature than those who had HMD alone, but the difference was not significant. The one difference between the groups was in the frequency of fits which were recorded in 22 of 51 infants who died with HMD plus IVH and in 6 of 49 who died with HMD alone $(P<0.001)$.

In order to gain some measure of the possible relation of IVH to the severity of HMD we compared the figures for acid-base status and the alkali therapy given to those babies in the 2 groups who survived for 12 hours or more (Table IV). There was no significant difference between the groups with respect to the lowest $p \mathrm{H}$, lowest $\mathrm{PaO}_{2}$, or highest $\mathrm{PaCO}_{2}$ recorded during life. Since similar $p \mathrm{H}$ readings might conceal a genuine difference between the groups in terms of metabolic acidosis, the base deficit indicated by each individual set of blood gas figures was calculated from

TABLE III

Clinical features of infants of 30-37 weeks' gestation who died with HMD (Hammersmith, 1966-73)

\begin{tabular}{|c|c|c|c|}
\hline & HMD & $\mathrm{HMD}+\mathrm{IVH}$ & $\mathbf{P}$ \\
\hline $\begin{array}{l}\text { No. of cases } \\
\text { Maternal age (years) } \\
\text { Number of primigravidae } \\
\text { Length of labour (h) } \\
\text { Incidence of caesarean section } \\
\text { Birthweight (g) } \\
\text { Gestation (w) } \\
\text { Sex ratio, M/F } \\
\text { Intubation at birth } \\
\text { Age at death (h) } \\
\text { Time on ventilator (h) } \\
\text { Incidence of fits }\end{array}$ & $\begin{array}{l}\quad 49 \\
25 \cdot 8 \pm 6 \cdot 7 \\
29(59 \%) \\
10 \cdot 1(1-28) \\
18(37 \%) \\
1880 \pm 550 \\
33 \cdot 4 \pm 2 \cdot 3 \\
1 \cdot 45 \\
21(43 \%) \\
41 \cdot 9(3-144) \\
22 \cdot 1(0-126) \\
6(12 \%)\end{array}$ & $\begin{array}{l}\quad 51 \\
26 \cdot 8 \pm 5 \cdot 9 \\
34(67 \%) \\
9 \cdot 0(1-24) \\
19(37 \%) \\
1740 \pm 450 \\
32 \cdot 7 \pm 2 \cdot 1 \\
\quad 1 \cdot 32 \\
30(59 \%) \\
40 \cdot 5(6-198) \\
17 \cdot 9(0-169) \\
22(43 \%)\end{array}$ & $\begin{aligned} & 0.18 \\
& 0.5 \\
& 0.89 \\
& 0.8 \\
& 0.23 \\
& 0.12 \\
&>0.95 \\
& 0.17 \\
& 0.46 \\
& 0.52 \\
&<0.001\end{aligned}$ \\
\hline
\end{tabular}

Note: Mean figures quoted $\pm 1 \mathrm{SD}$ or mean (range) if non-normal distribution. 
TABLE IV

Acid-base status and alkali therapy during life in infants of 30-37 weeks' gestation who died with HMD at 12 hours of age or more

\begin{tabular}{|c|c|c|c|}
\hline & HMD & HMD + IVH & $\mathbf{P}$ \\
\hline $\begin{array}{l}\text { No. of cases } \\
\text { Lowest } \mathrm{pH} \\
\text { Lowest } \mathrm{PaO}_{2} \\
\text { Highest } \mathrm{PaCO}_{2} \\
\text { No. of readings indicating metabolic acidosis } \\
\text { Hours of continuous metabolic acidosis } \\
\text { Total alkali (mmol/kg per h) } \\
\text { Total bicarbonate }(\mathrm{mmol} / \mathrm{kg} \text { per h) } \\
\text { Total THAM (mmol/kg per h) }\end{array}$ & $\begin{array}{l}\quad 41 \\
7 \cdot 03 \pm 0 \cdot 13 \\
26 \cdot 5 \pm 9 \cdot 4 \\
69 \cdot 4 \pm 17 \cdot 5 \\
153(38 \cdot 5 \%) \\
7 \cdot 69(1-38) \\
0 \cdot 29(0-1 \cdot 37) \\
0 \cdot 21(0-1 \cdot 37) \\
0 \cdot 083(0-0 \cdot 45)\end{array}$ & $\begin{array}{l}\quad 45 \\
7 \cdot 01 \pm 0 \cdot 12 \\
24 \cdot 9 \pm 9 \cdot 7 \\
74 \cdot 2 \pm 18 \cdot 0 \\
137(43 \cdot 9 \%) \\
6 \cdot 05(0-19) \\
\star 0 \cdot 39(0-1 \cdot 08) \\
\star 0 \cdot 30(0-0 \cdot 93) \\
\star 0 \cdot 097(0-0 \cdot 34)\end{array}$ & $\begin{array}{l}0 \cdot 79 \\
0 \cdot 33 \\
0 \cdot 16 \\
0 \cdot 2 \\
0 \cdot 82 \\
0 \cdot 02 \\
0 \cdot 02 \\
0 \cdot 35\end{array}$ \\
\hline
\end{tabular}

Note: Mean figures quoted \pm 1 SD or mean (range) if non-normal distribution.

$\star$ Based on 41 cases as information on alkali therapy was incomplete in 4 infants.

the standard Siggaard-Anderson nomogram and categorized as indicating a metabolic acidosis if the base excess was $<-10 \mathrm{mEq} / \mathrm{l}$, probable metabolic acidosis if base excess was $<-5 \mathrm{mEq} / \mathrm{l}$, and normal if it was $>-5 \mathrm{mEq} / 1$. The proportion of readings indicating a metabolic acidosis and the length of time during which all readings indicated a metabolic acidosis did not differ significantly between the groups. There was, however, a significant difference in the total quantity of alkali (expressed in $\mathrm{mmol} / \mathrm{kg}$ birthweight) given during life, and in the total quantity of sodium bicarbonate given during life. The quantity of THAM given during life, though greater in the IVH group, was not significant. Calculation of drug dosages in terms of osmolar load did not alter the significance of any comparison.

As it was considered that any effect of alkali therapy might be cumulative over a period of several hours we also compared the groups with respect to the maximum quantities of alkali given over any 12-hour period of life and the acid-base changes during that period (Table V). Again, there was no significant difference between the groups with respect to lowest $p \mathrm{H}$, lowest $\mathrm{PaO}_{2}$, or proportion of readings indicating a metabolic acidosis. The highest $\mathrm{PaCO}_{2}$ was significantly greater in the IVH group than in those with HMD alone. Maximum alkali dosage and maximum sodium bicarbonate dosage given during any 12hour period were significantly greater in the IVH group than in the non-IVH group. Maximum THAM dosage alone was again not significantly different between the groups.

Despite the lack of any demonstrable difference in severity of acidosis between the groups we considered the possibility that high alkali dosage might have been administered after the occurrence of IVH and in response to metabolic acidosis associated with it. Examination of the case notes of the 2 groups of infants did not show any consistent difference in the pattern of clinical deterioration. Episodes of rapid deterioration diagnosed during life as due to IVH were recorded in infants of both groups. Gradual deterioration without a dramatic collapse was also recorded in infants of either group.

\section{TABLE V}

Acid-base status and alkali therapy during 12 hours of maximum treatment in infants of 30-37 weeks' gestation who died with $H M D$

\begin{tabular}{|c|c|c|c|}
\hline & HMD & HMD + IVH & $\mathbf{P}$ \\
\hline $\begin{array}{l}\text { No. of cases } \\
\text { Lowest } \mathrm{pH} \\
\text { Lowest } \mathrm{PaO}_{2} \\
\text { Highest } \mathrm{PacO}_{2} \\
\text { No. of readings indicating metabolic acidosis } \\
\text { Total alkali (mmol/kg) } \\
\text { Bicarbonate (mmol/kg) } \\
\text { THAM (mmol/kg) }\end{array}$ & $\begin{array}{l}41 \\
7 \cdot 02 \pm 0 \cdot 11 \\
30 \cdot 5 \pm 11 \cdot 6 \\
60 \cdot 5 \pm 17 \cdot 8 \\
96(65 \cdot 7 \%) \\
6 \cdot 34(0-20 \cdot 2) \\
4 \cdot 45(0-14 \cdot 1) \\
2 \cdot 11(0-9 \cdot 3)\end{array}$ & $\begin{array}{l}41 \\
7 \cdot 03 \pm 0 \cdot 14 \\
27 \cdot 5 \pm 11 \cdot 7 \\
72 \cdot 7 \pm 19 \cdot 0 \\
86(56 \cdot 2 \%) \\
10 \cdot 21(0-26 \cdot 8) \\
8 \cdot 01(0-21 \cdot 7) \\
2 \cdot 85(0-12 \cdot 9)\end{array}$ & $\begin{array}{l}0.84 \\
0 \cdot 16 \\
0 \cdot 008 \\
0 \cdot 13 \\
<0 \cdot 001 \\
<0 \cdot 001 \\
0 \cdot 24\end{array}$ \\
\hline
\end{tabular}

Note: Mean figures quoted \pm 1 SD or mean (range) if non-normal distribution. 
Alkali dosage in survivors from respiratory distress syndrome (RDS) and in babies with GLH. We investigated alkali dosage given to survivors by looking at the maximum given over 12 hours to the 35 babies who survived after ventilator therapy for respiratory failure in RDS during the period of our study. The greatest quantity of alkali given over any 12-hour period to any survivor was $9.66 \mathrm{mmol} / \mathrm{kg}$ and the mean of the maximum values was $4.49 \mathrm{mmol} / \mathrm{kg}$ (Fig. 3).

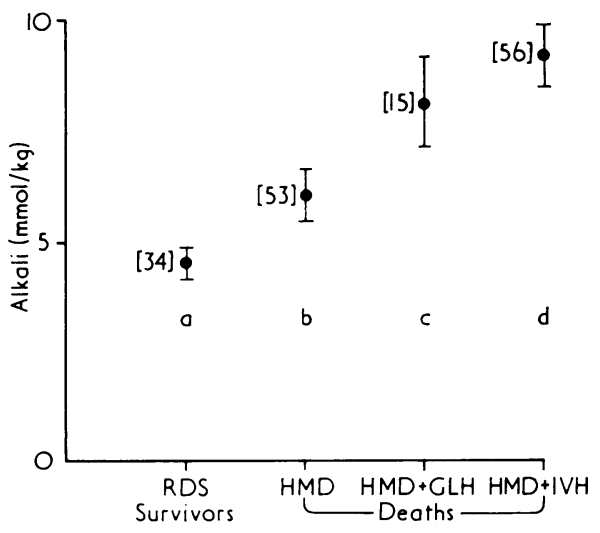

FIG. 3.-Maximum 12-hour alkali dosage expressed as mean $\pm S E M$ of survivors of severe respiratory distress syndrome (RDS) (ventilated) compared with deaths with $H M D, H M D+G L H$ (germinal layer haemorrhage), and HMD $+I V H$. Numbers in each group in parentheses. Statistical comparisons (Wilcoxon's Rank Sum test) $a: b$ and $c: d$, not significantly different; $a: c, P=0 \cdot 0012$; $a: d, P<0.0001 ; b: c, P=0.02 ; b: d, P<0.0001$.

Of 18 babies with HMD who had GLH without rupture into the ventricles, 15 had lived for 12 hours or more. The mean of the values for maximum alkali dosage given over a 12-hour period in this group was $8 \cdot 12 \mathrm{mmol} / \mathrm{kg}$ birthweight.

In Fig. 3 the maximum 12-hour alkali dose in these 2 groups is compared with those given to babies who died with HMD alone or HMD with IVH. Infants of all gestational ages have been included. It can be seen that the dosage given to babies with HMD and GLH is intermediate between that given to babies with HMD alone and that given to babies with a fully developed IVH.

Alkali dose level associated with development of GLH and IVH. IVH was found in many babies below 30 week's gestation who had been given relatively low doses of alkali (Fig. 4). At 30 weeks' gestation or above the dosage level

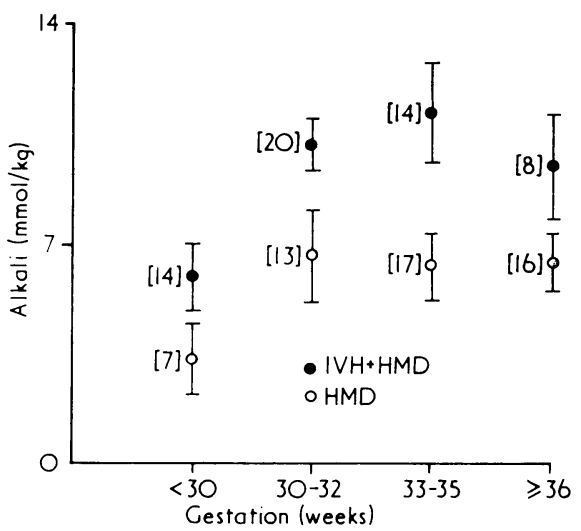

FIG. 4.-Maximum 12-hour alkali dosage, expressed as mean $\pm S E M$, in $I V H+H M D$ and HMD groups, by gestation. Numbers in each group in parentheses.

administered to the two main groups of babies did not vary significantly with increasing gestation. On examining the alkali dosage given to babies who died with HMD at 30 weeks' gestation or more, the occurrence of GLH with or without IVH seemed to be related to a maximum 12-hour alkali dose level of $7 \mathrm{mmol}$ or more. GLH with or without IVH was present in 13 of the 43 infants given less than $7 \mathrm{mmol}$ alkali per $\mathrm{kg}$ and in 42 of the 58 given $7 \mathrm{mmol}$ alkali per kg or more $\left(\chi^{2}=16 \cdot 05, \mathrm{P}<0 \cdot 001\right)$.

\section{Discussion}

The initial finding which determined the course of this study was the marked variation in frequency distribution of gestational age of babies who died with IVH according to whether or not they also had HMD. As the finding was readily demonstrable in the population of babies born at Hammersmith as well as in those admitted after birth we inferred that some factor or factors associated with HMD must cause nearly all cases of IVH which occur at above 30 weeks' gestation. The frequent coexistence of the two conditions has been noted by a number of workers but the gestational difference has not been pointed out. Fedrick and Butler (1970b) suggested that the coincidence of HMD and IVH occurring at necropsy more frequently than expected by chance could be explained on the assumption that IVH caused the death of some babies with HMD who would otherwise have survived. Recent papers (Harcke et al., 1972; Leech and Kohnen, 1974; Tsiantos et al., 1974) have reiterated the significance of the association but have not disproved the argument that Fedrick and Butler put forward to explain it. The gesta- 
tional age patterns seen in the present study clearly refute this explanation as far as our own material is concerned.

Studies on our hospital population confirm recent findings (Machin, 1975) of an absolute increase in the incidence of IVH as compared to the 1958 Perinatal Mortality Survey. Part of our high incidence results from the large number of low birthweight infants in our population, but there is a trebled incidence in deaths from IVH in the 1000$1500 \mathrm{~g}$ birthweight group. Most of these deaths were in babies with HMD. We have not been able to explain this finding on the basis of an increased survival time of babies who ultimately die with HMD, as the age at death of our babies with HMD was identical to that reported by Fedrick and Butler (1970a). A recent report (Anderson et al., 1976) shows a $60 \%$ increase in deaths from IVH with HMD in babies born at Simpson Memorial Pavilion, Edinburgh, over the years 1971-74, as compared to 1956-59, though total IVH incidence has not altered due to a concomitant fall in deaths from IVH without HMD. It is difficult to avoid the conclusion that some factor related to clinical management of babies with RDS has played a role in the increased death rate from IVH with HMD over a period when perinatal mortality as a whole has continued to decline.

The two groups of infants (i.e. those with HMD with or without additional IVH at gestations of 30 weeks or more) whose records we have studied in order to clarify the relation between HMD and IVH have proved remarkably similar with regard to many of the factors previously postulated as associated with the development of IVH including maternal parity (Fedrick and Butler, 1970b), incidence of birth asphyxia (Amiel, 1964), and severity of hypoxia or metabolic acidosis (Leech and Kohnen, 1974).

The two factors in which the groups differed markedly were the incidence of fits and the quantity of alkali administered. It seems reasonable to assume that fits occur as a result rather than as a cause of IVH since there is evidence that the onset of fits coincides with the haemorrhage (Tsiantos et al., 1974). The main problem lies in the interpretation of the difference in alkali dosage. This is critically dependent on whether the drugs were mainly given before or after the development of IVH. Unfortunately, retrospective diagnosis of the occurrence of an IVH is extremely difficult though pinpointing the probable time to within a brief period may be possible if frequent haematocrit readings or special investigations have been done (Harrison, Heese, and Klein, 1968; Tsiantos et al.,
1974). In the absence of such methods descriptions of episodes of sudden collapse recorded in the clinical notes have to be relied upon. It was impossible to make such a retrospective diagnosis in our study since episodes of collapse were recorded for infants without IVH, might be absent in records of babies with IVH, or might have been recorded on more than one occasion.

A widely held belief is that infants with IVH are distinctive in having a severe metabolic acidosis which is resistant to alkali therapy (Harrison et al., 1968). If such were the case it could well explain the more liberal use of alkali therapy in this group of infants. We have been unable to establish that babies with HMD who develop IVH have a more severe or more persistent acidosis than do those who die with HMD without IVH.

The question remains as to what prompted treatment of the IVH group with large doses of alkali if it was not the severity of the acidosis. Severe cardiovascular collapse in babies with IVH may have provoked an illogical treatment response. Both Roberton and Howat (1975) and Anderson et al. (1976) believe that alkali was given, in their respective series, mainly after IVH had occurred. The alternative explanation is that excessive alkali therapy when given to babies with HMD has caused or contributed to the development of IVH. The high alkali dosage given to babies with a GLH which had not ruptured into the ventricular system is of interest in this connection.

This argument cannot be resolved without direct experimentation (preferably on some suitable animal model). The widely quoted experiments of Luttrell, Finberg, and Drawdy (1959) confirm that hyperosmolar solutions can cause intracranial haemorrhage but are not directly relevant to IVH in the newborn. However, it seems reasonable to consider whether there is any theoretical way in which high alkali dosage could cause IVH and whether a reduction in alkali usage is likely to prove harmful. Simmons et al. (1974) suggested that the high serum sodium levels resulting from administration of sodium bicarbonate were the possible cause of the haemorrhage. Baum and Roberton (1975) have shown that both bicarbonate and THAM may cause a significant rise in blood volume particularly after a rapid intravenous injection. The damaging effect could result from the hyperosmolar load rather than from the action of any one ion in particular. Recent studies on the vascular anatomy of the germinal layer (Hambleton and Wigglesworth, 1976) indicate that the primary bleeding occurs at capillary level, possibly as a result of a rise in arterial pressure. The hypercapnoea typical of 
RDS may contribute to the causation of IVH by provoking cerebral vasodilatation and increased cerebral blood flow. Sodium bicarbonate administration can dramatically accentuate this effect (Baum and Roberton, 1975). Acidosis is known to impair the sensitivity of vessel walls to circulating catecholamines (Porcelli and Bergofsky, 1971). Correction of acidosis with alkali could provoke hypertension by restoring normal sensitivity. THAM is an intensely irritant solution and causes tissue damage particularly if injected outside the vessels. With a right-to-left shunt at atrial level it is possible that high concentrations might reach the germinal layer capillary bed and cause direct damage to the delicate vessel walls. There are thus a number of theoretical mechanisms to suggest how alkali solutions could cause intracranial haemorrhage.

Simmons et al. (1974) recommended that bicarbonate should be administered at a rate of not more than $8 \mathrm{mEq} / \mathrm{kg}$ over any 24 hours. In our infants with IVH an equivalent dosage of bicarbonate was given on average within a period of 12 hours. Irrespective of any possible causal association with IVH, many paediatricians involved in neonatal intensive care now advocate restraint in the use of alkali solutions and recommend administration by slow injection or infusion (Reynolds and Taghizadeh, 1974; Baum and Roberton, 1975). Favourable results of treatment of RDS are reported from units where such methods have been adopted (Reynolds and Taghizadeh, 1974; Roberton and Tizard, 1975).

The use of oxygen therapy to improve tissue oxygenation, with additional support to respiration by means of continuous distending pressure techniques and mechanical ventilation may allow the infant with RDS to correct his own acid-base status. This is probably of more benefit than an attempt to titrate the blood $p \mathrm{H}$ back to normal with hypertonic alkali solutions.

We thank the paediatricians whose discussions have helped us in analysing and interpreting our results, including Drs. N. R. C. Roberton, L. S. James, and J. C. Sinclair, and several neuropathologists for help in examining neonatal brains, including Drs. Sabina Strich, J. M. Anderson, G. A. De Leon, and P. D. Lewis.

The work has been supported by a grant from the DHSS.

\section{REFERENCES}

Amiel, C. (1964). Hémorrbagies cérébrales intra-ventriculaires chez le prématuré. II. Les éléments du diagnostic clinique. Biologia Neonatorum, 7, 57.
Anderson, J. M., Bain, A. D., Brown, J. K., Cockburn, F., Forfar, J. O., Machin, G. A., and Turner, T. L. (1976). Hyalinemembrane disease, alkaline buffer treatment, and cerebral intraventricular haemorrhage. Lancet, 1, 117.

Baum, J. D., and Roberton, N. R. C. (1975). Immediate effects of alkaline infusion in infants with respiratory distress syndrome. Fournal of Pediatrics, 87, 255.

Chessells, J. M., and Wigglesworth, J. S. (1972). Coagulation studies in preterm infants with respiratory distress and intracranial haemorrhage. Archives of Disease in Childhood, 47, 564.

Cole, V. A., Durbin, G. M., Olaffson, A., Reynolds, E. O. R., Rivers, R. P. A., and Smith, J. F. (1974). Pathogenesis of intraventricular haemorrhage in newborn infants. Archives of Disease in Childhood, 49, 722.

Davies, P. A., Robinson, R. J., Scopes, J. W., Tizard, J. P. M., and Wigglesworth, J. S. (1972). Medical Care of Newborn Babies. Clinics in Developmental Medicine, No. 44/45. Heinemann, London.

Fedrick, J., and Butler, N. R. (1970a). Certain causes of neonatal death. I. Hyaline membranes. Biologia Neonatorum, 15, 229.

Fedrick, J., and Butler, N. R. (1970b). Certain causes of neonatal death. II. Intraventricular haemorrhage. Biologia Neonatorum, 15, 257.

Gray, O. P., Ackerman, A., and Fraser, A. J. (1968). Intracranial haemorrhage and clotting defects in low-birth-weight infants. Lancet, 1, 545.

Hambleton, G., and Wigglesworth, J. S. (1976). Origin of intraventricular haemorrhage in the preterm newborn infant. Archives of Disease in Childhood, 51, 651.

Harcke, H. T., Naeye, R. L., Storch, A., and Blanc, W. A. (1972). Perinatal cerebral intraventricular hemorrhage. fournal of Pediatrics, 80, 37.

Harrison, V. C., Heese, H. de V., and Klein, M. (1968). Intracranial haemorrhage associated with hyaline membrane disease. Archives of Disease in Childhood, 43, 116.

Heird, W. C., Dell, R. B., Price, T., and Winters, R. W. (1972). Osmotic effects of infusion of THAM. Pediatric Research, 6, 495.

Larroche, J. C. (1964). Hémorrhagies cérébrales intra-ventriculaires chez le prématuré. I. Anatomie et pathophysiologie. Biologia Neonatorum, 7, 26.

Leech, R. W., and Kohnen, P. (1974). Subependymal and intraventricular hemorrhages in the newborn. American fournal of Pathology, 77, 465.

Luttrell, C. N., Finberg, L., and Drawdy, L. P. (1959). Hemorrhagic encephalopathy induced by hypernatremia. Archives of Neurology, 1, 153.

Machin, G. A. (1975). A perinatal mortality survey in South-East London, 1970-73: the pathological findings in 726 necropsies. fournal of Clinical Pathology, 28, 428.

Porcelli, R. J., and Bergofsky, E. H. (1971). Effect of pH on pulmonary pressor responses to humoral agents. Fournal of Applied Physiology, 31, 679.

Reynolds, E. O. R., and Taghizadeh, A. (1974). Improved prognosis of infants mechanically ventilated for hyaline membrane disease. Archives of Disease in Childhood, 49, 505.

Roberton, N. R. C., and Howat, P. (1975). Hypernatraemia as a cause of intracranial haemorrhage. Archives of Disease in Childhood, 50, 938.

Roberton, N. R. C., and Tizard, J. P. M. (1975). Prognosis for infants with idiopathic respiratory distress syndrome. British Medical fournal, 3, 271.

Simmons, M. A., Adcock, E. W., Bard, H., and Battaglia, F. C. (1974). Hypernatremia and intracranial hemorrhage in neonates. New England fournal of Medicine, 291, 6.

Towbin, A. (1968). Cerebral intraventricular hemorrhage and subependymal matrix infarction in the fetus and premature newborn. American fournal of Pathology, 52, 121.

Tsiantos, A., Victorin, L., Relier, J. P., Dyer, N., Sundell, H., Brill, A. B., and Stahlman, M. (1974). Intracranial hemorrhage in the prematurely born infant. Timing of clots and evaluation of clinical signs and symptoms. Fournal of Pediatrics, 85, 854 .

Correspondence to Dr. J. Wigglesworth, Department of Paediatrics and Neonatal Medicine, Institute of Child Health, Hammersmith Hospital, Du Cane Road, London W12. 